\title{
UNILOCULAR OMENTAL CYST IN ADULT FEMALE PRESENTING AS HUGE ABDOMINAL LUMP: A RARE CASE REPORT
}

Himansu Roy ${ }^{1}$, Krishnendu Sardar², Pratyusha Bhattacharjee ${ }^{3}$

\section{HOW TO CITE THIS ARTICLE:}

Himansu Roy, Krishnendu Sardar, Pratyusha Bhattacharjee. "Unilocular Omental CYST in Adult Female Presenting as Huge Abdominal Lump: A Rare Case Report". Journal of Evolution of Medical and Dental Sciences 2015; Vol. 4, Issue 38, May 11; Page: 6687-6691, DOI: 10.14260/jemds/2015/969

ABSTRACT: Omental cysts are rare entity with a prevalence of $1: 1,000,000$ in adults and in 1:20,000 in children. We are reporting a case of a 30 year female patient with abdominal lump over epigastrium and left hypochondrium for 6 months; diagnosed on laparotomy as uniloculated omental cyst originating from lesser omentum. Omental cyst is a challenging diagnostic entity with varied presentations and a wide range of differential diagnosis has to be kept in mind.

INTRODUCTION: Omental cysts have a prevalence of 1:1,000,000 in adults and in 1:20,000 in children.[1] Omental cysts are more commonly seen in children below 15 years of age with mean age of occurence at 4.9 years, but may occur in adults rarely.[2] We are reporting a case of a 30 year female patient with abdominal lump over epigastrium and left hypochondrium diagnosed on laparotomy as uniloculated omental cyst originating from lesser omentum. It is an interesting finding as omental cyst itself is a rare entity according to above mentioned data and also more common in pediatric age group. But in this case a 30 yrs old female from eastern India presented with such a finding which also created a diagnostic challenge.

CASE REPORT: A 30 year non-diabetic, normotensive female patient presented with abdominal lump over epigastrium and left hypochondrium associated with mild vague abdominal pain for last 6 months. On examination, lump was $25 \times 25 \mathrm{~cm}$ in size, globular in shape, well- circumscribed, smooth on surface, tense cystic in consistency, slightly mobile in sidewise direction but restricted mobility on above downwards. The mass was ill-defined on deep palpation, had no cough impulse and did not change in knee elbow position (located on parietes). It became less prominent in leg rising test and was dull on percussion.

The differential diagnosis which came to our mind were pseudocyst of pancreas, cystadenoma of pancreas, cystadenocarcinoma of pancreas, omental cyst, hydatid cyst of liver, simple cyst of liver and lump originating from left adrenal gland as the mass presented over the epigastrium and left hypochondrium. Routine blood investigations did not yield any abnormality. Contrast enhanced computed tomography (CECT) scan of whole abdomen showed well- circumscribed hypodense cystic lesion with incomplete septa extending superiorly to abutt the body \& tail of pancreas, inferiorly to abutt the left kidney and anteriorly upto anterior abdominal wall. [Fig. 1] The origin of the mass could not be appreciated on CT. The measurement was $14.6 \mathrm{~cm} \times 14.8 \mathrm{~cm}$ and it extended craniocaudally for approx $16 \mathrm{~cm}$ from D12 to L4. On laparotomy cyst was found enclosed within the layers of lesser omentum [Fig. 2A], adhered to the body of pancreas [Fig. 2B, 2C]. The cyst was enucleated [Fig. 2D] and the aspirated fluid was sent for study which showed $65 \%$ mesothelial cell only (negative for malignancy). Fluid amylase and lipase levels were within normal limit. On histopathological evaluation a cyst wall lined by flattened to cuboidal endothelium was found [Fig. 2E]. No malignant or dysplastic cell was identified. After enucleation, hemostasis was done and 
abdomen was closed in layers. Patient's post-operative period was uneventful and she is regular in her follow-up visit in OPD and currently doing well.

DISCUSSION: According to Conzo et al, mesentric and omental cysts are regarded as congenital abdominal lesions.[3] The well accepted pathogenetic mechanism of its origin, suggested by Gross, is benign proliferation of ectopic lymphatics in the mesentry which do not have communication with rest of the lymphatic system. ${ }^{4]}$

Omental cysts may be simple or multiple and can be unilocular or multilocular. They can contain hemorrhagic, serous, chylous, or infected fluid. Omental cysts can be an incidental finding during laparotomy for another condition. They may manifest as a chronic or acute abdomen. Chronic symptoms present as progressive abdominal distension and pain like in our case. The mass can be huge, resembling ascites.[5] The patient may also present with complications like torsion, haemorrhage and infection. ${ }^{[6]}$ They may produce mass effect can cause intestinal obstruction, infection, or hemorrhage.[7]

A similar case was reported by Sanjeev Kumar et al..[8] in 2009 but in their case the huge omental cyst mimicked ovarian cyst clinically. In our case differential diagnoses were pseudocyst of pancreas, cystadenoma of pancreas, cystadenocarcinoma of pancreas, omental cyst, hydatid cyst of liver, simple cyst of liver and lump originating from left adrenal gland as the mass presented over the epigastrium and left hypochondrium. In their case on laparotomy an omental cyst lined by cuboidal epithelium was found.

Another case was reported by Matthew H Nett et al,[9] in 2010 in which the huge omental cyst mimicked ascites and on laparotomy a multiloculated omental cyst having haemorrhagic fluid was found.

P. A. Ramani and I. Vani[10] in 2015 reported a massive omental cyst clinically mimicking ovarian cyst or ascites. Cyst was lined by flattened endothelium and had lymphoid tissue, increased vascularity and without any evidence of malignancy.

As omental cysts lack specific signs and symptoms, their diagnosis can be challenging and a high index of suspicion is required. Good imaging helps to plan the surgery. CT scan of abdomen can show the details of location and relation to other structures. Ultrasonography is also helpful especially for real time imaging of omental cysts.

The diagnosis is apparent on laparotomy and has to be confirmed histologically. The mesentric and omental cysts can be classified histologically according to updated classification recommended by Marc de Perrot.[11] It is as follows:

\begin{tabular}{|c|c|c|}
\hline Cyst type & Grossly & Microscopy \\
\hline $\begin{array}{c}\text { Simple lymphatic } \\
\text { cyst (chylous cyst, } \\
\text { lymphocele) }\end{array}$ & $\begin{array}{c}\text { Small }(1-5 \mathrm{~cm}), \\
\text { unilocular, } \\
\text { thin-walled }\end{array}$ & $\begin{array}{c}\text { Lining: flat endothelial cells. } \\
\text { Wall: smooth muscle fibers, lymphoid } \\
\text { aggregates }\end{array}$ \\
\hline Lymphangioma & $\begin{array}{c}\text { Large }(>5 \mathrm{~cm}), \text { multilocular } \\
\text { or multiple }\end{array}$ & Same as lymphocele \\
\hline $\begin{array}{c}\text { Enteric duplication } \\
\text { Cyst }\end{array}$ & $\begin{array}{c}\text { Mostly unilocular, } \\
\text { Some multilocular; } \\
\text { Small bowel mesentery }\end{array}$ & Wall: muscular layer with nervous plexus \\
\hline
\end{tabular}


CASE REPORT

\begin{tabular}{|c|c|c|}
\hline Enteric cyst & $\begin{array}{c}\text { Unilocular, of } \\
\text { Mesentery and mesocolon }\end{array}$ & $\begin{array}{c}\text { Lining: enteric Mucosa. } \\
\text { Wall: connective tissue Only }\end{array}$ \\
\hline $\begin{array}{c}\text { Embryonic vestigial } \\
\text { Urogenital cyst }\end{array}$ & $\begin{array}{c}\text { Variable size, } \\
\text { unilocular, multilocular }\end{array}$ & $\begin{array}{c}\text { Wolffian or Mullerian } \\
\text { Duct remnants }\end{array}$ \\
\hline $\begin{array}{c}\text { Mature cystic } \\
\text { Teratomas }\end{array}$ & Has solid areas & $\begin{array}{c}\text { Admixture of benign ectoderm, } \\
\text { endoderm and mesoderm. }\end{array}$ \\
\hline $\begin{array}{c}\text { Non-Pancreatic } \\
\text { Pseudocysts }\end{array}$ & $\begin{array}{c}\text { Variable size, } \\
\text { Thick walled, unilocular and } \\
\text { multilocular }\end{array}$ & $\begin{array}{c}\text { No epithelial lining. } \\
\text { Thick fibrous wall }\end{array}$ \\
\hline \multicolumn{2}{|c|}{ Table 1: Classification of mesenteric and omental cysts histopathologically } \\
according to updated classification recommended by Marc de Perrot
\end{tabular}

According to Rosai and Ackerman, ${ }^{[12]}$ cystic lymphangioma of omentum represents the single most frequent tumor of omentum in children and its gross and microscopic appearance recapitulates that of cystic hygroma of neck. The preferred treatment is complete excision of the cyst to prevent recurrence.[13]

\section{REFERENCES:}

1. Theodoridis TD, Zepiridis L, Athanatos D, Tzevelekis F, Kellartzis D, Bontis JN. Laparoscopic management of mesenteric cyst: a case report. Cases J. 2009; 2: 132.

2. Takiff H, Calabria R, Yin L, Stabile BE. Mesenteric cysts and intra-abdominal cystic lymphangiomas. Arch Surg. 1985; 120: 1266-9.

3. Conzo G, Vacca R, Grazia Esposito M, Brancaccio U, Celsi S, Livrea A: Laparoscopic treatment of an omental cyst: a case report and review of the literature. Surg Laparosc Endosc Percutan Tech 2005, 15: 33-35.

4. Prakash A, Agrawal A, Gupta RK, Sanghvi B, Parelkar S. Early management of mesenteric cyst prevents catastrophes: A single centre analysis of 17 cases. Afr J Paediatr Surg 2010; 7: 140-3.

5. Devrim L, Oktar S, cel Cem C, HakanO Z: Huge omental cyst simulatingascites. European Journal of Radiology Extra 2005, 54: 55-57.

6. Hardin, W. J. , Elliott, R. L. , Wesson, R. L. and Lowicki, E. M. Hemorrhagic mesenteric cyst simulating an acute abdomen. American Surgeon, 1967. 33, 733-736.

7. Menon P, Rao KL. Giant omental cyst masquerading as hemorrhagic ascites. Indian Pediatr 2005; 42 (4): 395-6.

8. Kumar S, Agrawal N, Khanna R, Khanna AK. Giant lymphatic cyst of omentum: a case report. Cases Journal 2009; 2: 23. Available from:

URL: http: //www. casesjournal. com/content/2/1/23. [Last accessed on 11/04/2015].

9. Nett MH, Vo NJ, Chapman T. Large omental cyst. Radiology Case Reports. [Online] 2010; 5: 388. Available from: URL: http: //www. radiology. Case reports. net/index. php/rcr/article/view/388/730. . [Last accessed on 11/04/2015].

10. Ramani PA, Vani I. A Rare Case of Massive Omental Cyst Mimicking as an Ovarian Cyst. Journal of Evidence based Medicine and Healthcare 2015 Jan 19; 2 (3): 278-282.

11. de Perrot M, Brundler M, Totsch M, Mentha G, Morel P. Mesenteric cysts. Towardless confusion? Digestive Surgery. 2000; 17: 323-8. 


\section{CASE REPORT}

12. Rosai J. Rosai and Ackerman's Surgical Pathology. 10 th ed. Vol. 2. Edinburgh: Elsevier; 2011. p. 2247.

13. Deshpande AA, Dalvi AN. Laparoscopic excision of a giant mesothelial omental cyst. J Min Access Surg 2012; 8: 57-8.

Fig 1:

A: CT scan of abdomen showing a mass of $25 \times 25 \mathrm{~cm}$ located in left hyochondrium.

B: Saggital cut showing mass localised in front of D12-L4.

C: Transverse cut showing mass abutting body of pancreas and posterior wall of stomach.
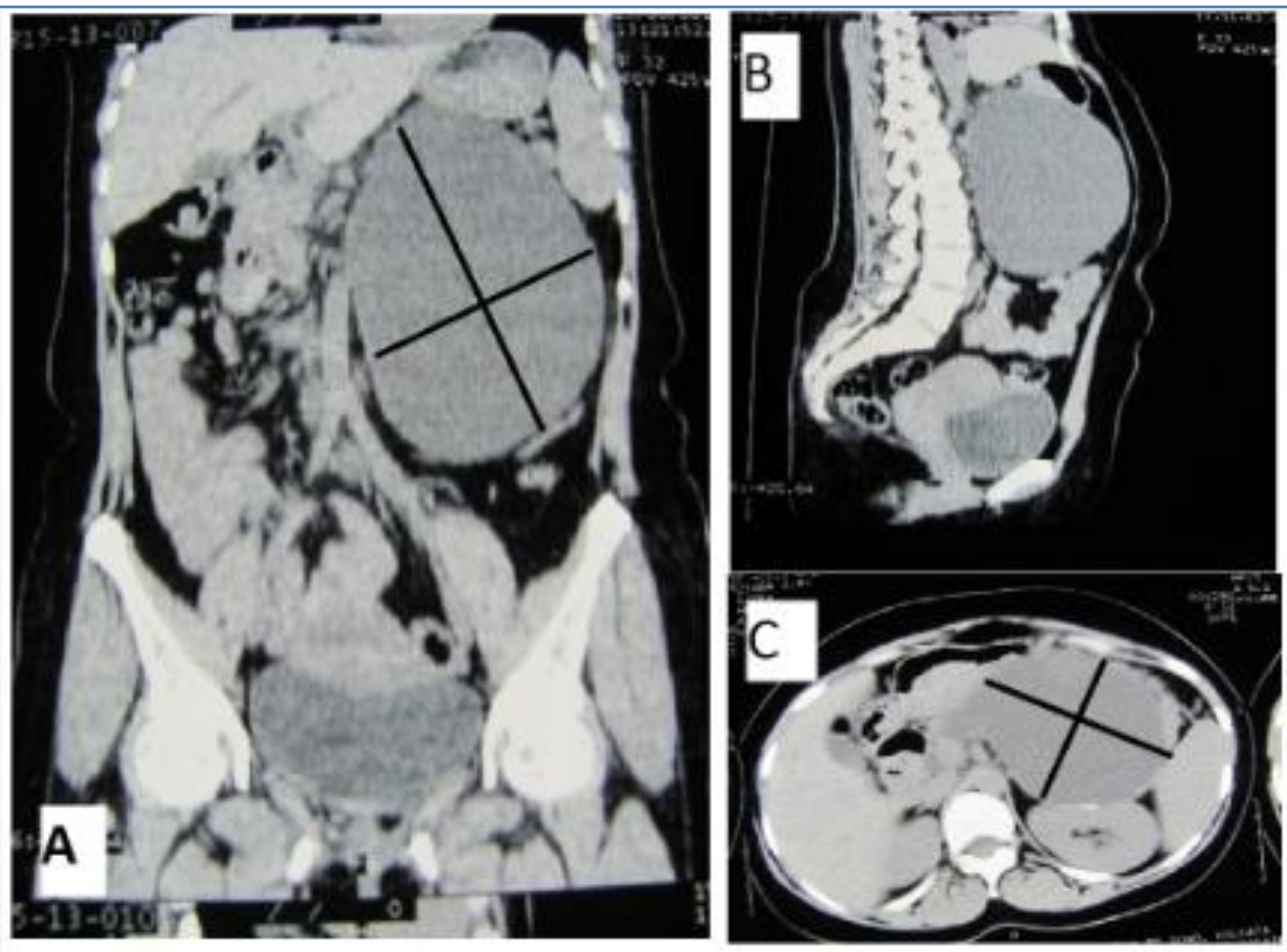

Fig. 1 (A, B, C) 


\section{CASE REPORT}

Fig. 2:

A: On laparotomy globular thin walled unilocular cyst enclosed by layers of omentum.

B \& C: Cyst abutting body of pancreas and stomach.

D: Enucleated cyst gross picture.

E: Cyst wall histological finding (x400, H \&E).
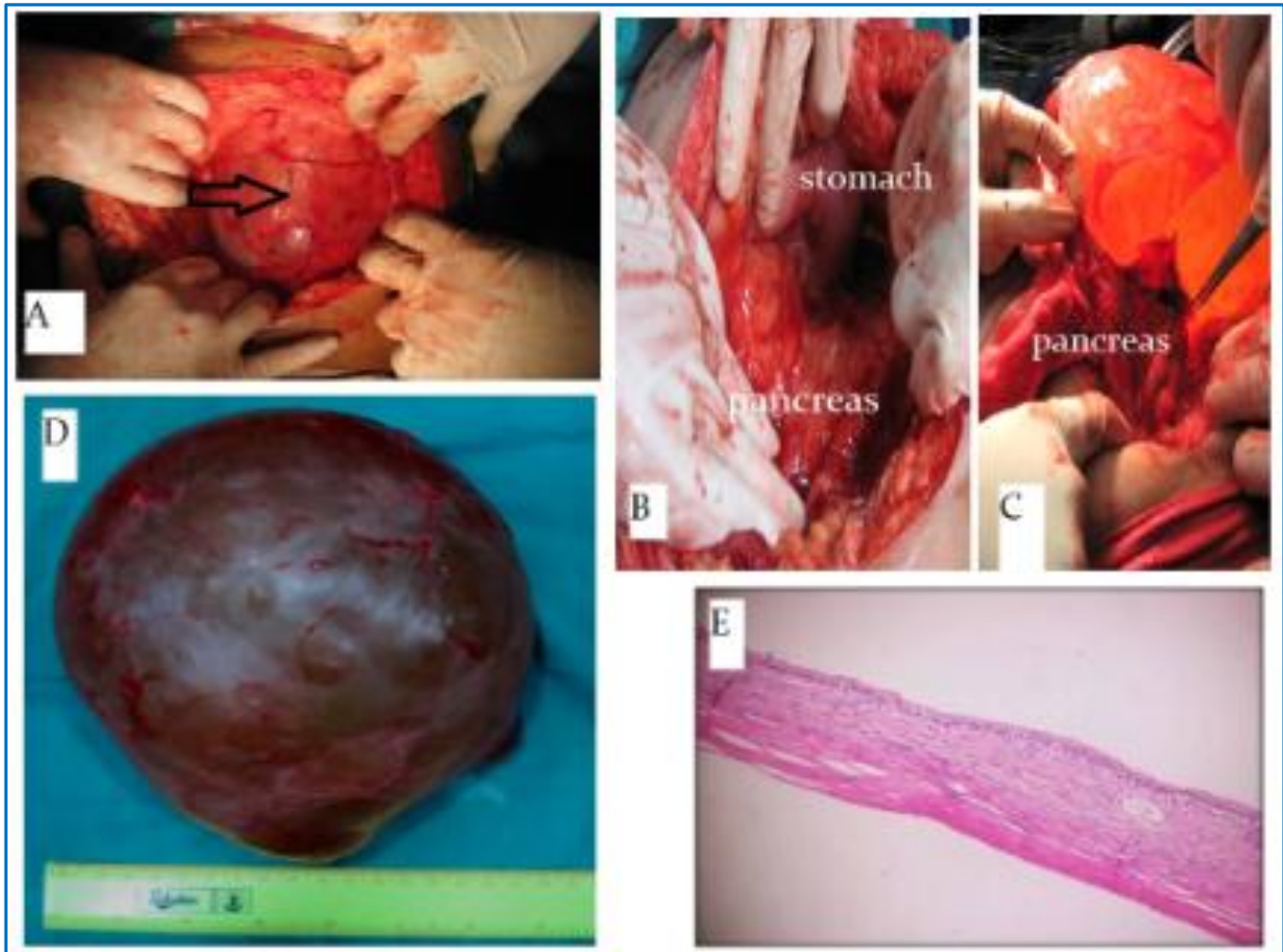

Fig. 2 (A, B, C, D, E)

\section{AUTHORS:}

1. Himansu Roy

2. Krishnendu Sardar

3. Pratyusha Bhattacharjee

\section{PARTICULARS OF CONTRIBUTORS:}

1. Associate Professor, Department of Surgery, Medical College, Kolkata.

2. RMO Cum Clinical Tutor, Department of Neurosurgery, Nilratan Sircar Medical College, Kolkata.

\section{FINANCIAL OR OTHER}

COMPETING INTERESTS: None
3. Post Graduate Trainee, Department of Pathology, Medical College, Kolkata.

\section{NAME ADDRESS EMAIL ID OF THE CORRESPONDING AUTHOR:}

Dr. Himansu Roy,

14/2, Naskar Para Lane,

Flat A/3, P.O, B. Garden,

Howrah-711103, West Bengal.

E-mail: dr_hroy007@yahoo.co.in

Date of Submission: 13/04/2015.

Date of Peer Review: 14/04/2015.

Date of Acceptance: 30/04/2015.

Date of Publishing: 11/05/2015. 